\title{
Effects of Inactive Vitamin D on Persistent Secondary Hyperparathyroidism in Patients on Hemodialysis
}

\author{
Mojgan Jalalzadeh, ${ }^{1,{ }^{*}}$ and Nouraddin Mousavinasab ${ }^{2}$ \\ ${ }^{1}$ Department of Nephrology, Loghman Hakim Hospital, Shahid Beheshti University of Medical Sciences, Tehran, IR Iran \\ ${ }^{2}$ Department of Biostatistics, Mazandaran University of Medical Sciences, Sari, IR Iran \\ "Corresponding author: Mojgan Jalalzadeh, Department of Nephrology, Loghman Hospital, Shahid Beheshti University of Medical Sciences, Tehran, IR Iran. Tel: \\ +98-2151025000, E-mail: jmojgan1341@gmail.com
}

Received 2016 December 24; Revised 2017 January 21; Accepted 2017 January 28.

\begin{abstract}
Background: Secondary Hyperparathyroidism (sHPT) is an important feature of chronic renal failure and contributes to the development of renal osteodystrophy. This study was carried out to assess 25(OH)D status and its effect on sHPT in patients on hemodialysis (HD).

Methods: A prospective experimental trial of $180 \mathrm{HD}$ patients (F: 81, M: 99, age > 14year) participated in the study. At base line, levels of 25(OH)D, intact Parathyroid Hormone (iPTH), Calcium (Ca), Phosphorous (P), Alkaline phosphatase (Alk p), and albumin of serum were measured. Patients with $25(\mathrm{OH})$ D deficiency $(<30 \mathrm{ng} / \mathrm{mL}$ ) were randomly divided to two groups: intervention (received $300,000 \mathrm{U} / \mathrm{IM}$ vitD3 at the beginning and after 2 months, if was necessary) and control (received placebo). After 2 and 4 months, the same biochemical markers were measured and efficacy of vitD3 on sHPT was assessed. Secondary Hyperthyroidism (sHPT) was defined as $\mathrm{iPTH}>300 \mathrm{pg} / \mathrm{mL}$.

Results: Serum 25(OH)D levels were deficient in $87.8 \%$ (n: 158) of subjects, and normal in $12.2 \%$ (n: 22). The prevalence of sHPT, according to $25(\mathrm{OH})$ D levels, was $71.5 \%(\mathrm{n}: 113)(<30 \mathrm{ng} / \mathrm{mL})$ and $40.9 \%(\mathrm{n}: 9)(\geq 30)$, respectively. There were 57 intervention and 56 control subjects. In the intervention group, 2 months after injections, $25(\mathrm{OH}) \mathrm{D}$ increased from $13.85 \pm 6.5$ to $48.5 \pm 20.7$ (P<0.001), iPTH was reduced from $567.2 \pm 276.7$ to $282.7 \pm 183.6$ ( $\mathrm{P}<0.001$ ), calcium from $9.10 \pm 0.5$ to $8.76 \pm 0.7$ ( $\mathrm{P}=0.021)$, Alk p from 553.37 \pm 495.6 to $393.4 \pm 419.5(\mathrm{P}<0.001)$, albumin from $3.87 \pm 0.5$ to $4.00 \pm 0.4(\mathrm{P}=0.06)$, and phosphorus from $4.90 \pm 1.2$ to $5.21 \pm 1.3(\mathrm{P}$ $=0.12)$. Since all cases were under appropriate treatment for SHPT, there was a significant reduction on the levels of iPTH $(\mathrm{P}=0.005)$ and Alk p $(\mathrm{P}=0.049)$, and slight increase in $25(\mathrm{OH}) \mathrm{D}$ level $(\mathrm{P}=0.08)$ in the control group. However, the amount of these changes was less than the intervention group.

Conclusions: These findings showed that 25(OH)D insufficiency was highly prevalent in HD cases and higher amount of 25(OH)D levels prevent sHPT.
\end{abstract}

Keywords: 25-Hydroxy Vitamin D, End Stage Renal Failure, Secondary Hyperparathyroidism, Hemodialysis

\section{Introduction}

The progression of kidney failure leads to loss of excretory activity and impairment of endocrine functions and mineral metabolism that affects many organ systems. Secondary secretion Parathyroid Hormone (sHPT) is a compensatory mechanism to restore normal levels of serum calcium and phosphorus concentrations, and is associated with high level of PTH(1). The SHPT and high calcium (Ca) $\times$ phosphorus $(\mathrm{P})$ product have been associated with the risk of bone fractures, cardiovascular morbidity and mortality, and parathyroidectomy (2-4).

Common causes of sHPT are associated with deficiency in vitamin $\mathrm{D}$, inadequate calcium foods, and chronic renal failure (5). In patients with uremia, to maintain normal metabolism of the bone, the serum level of PTH should be increased by a factor of two or three of normal cases (6).

Secondary HPT is caused by a complex disorder of min- eral metabolism involving low vitamin D and elevated PTH levels. The main regulator of $1-\alpha$-hydroxylase activity in the kidney is PTH and vitamin D is a regulator of PTH (7). In patients on Hemodialysis (HD), the mainstay of treatment of sHPT is use of activated vitamin D analogues (8), including nonselective agents such as Calcitriol (1, 25(OH)D3) (9).

Current kidney disease outcomes quality initiative (K/DOQI) recommends measuring serum levels of intact parathyroid hormone (iPTH), calcium and phosphorus in stage 3 to 4 chronic kidney disease (CKD) (9). The recommended levels for the iPTH is $150-300 \mathrm{pg} / \mathrm{mL}$, and active vitamin $\mathrm{D}$ should be administered for the patients. When the level of iPTH is more than $300 \mathrm{pg} / \mathrm{mL}$ (9), dosage of vitamin D has to be adjusted.

The NKF-K/DOQI guidelines also recommend that in patients with CKD stage 3 or 4 , who have elevated iPTH levels, 25(OH)D3 level should be measured (10) and if levels are less than $30 \mathrm{ng} / \mathrm{mL}$, precursor vitamin D supplement is rec- 
ommended $(10,11)$.

In the general population, low levels of 25(OH)D have been associated with increased PTH levels and studies have shown the precursor of vitamin D controls SHPT (12). However, the role of $25(\mathrm{OH}) \mathrm{D}$ in the treatment of renal osteodystrophy in HD patients remains to be determined.

In this study, we aimed at investigating the prevalence of $25(\mathrm{OH})$ vitamin D deficiencies in HD patients and then evaluate the effect of Vitamin D3 injections in controlling sHPT.

\section{Methods}

This study was conducted in four HD centers located in Tehran and Zanjan (Vali-e-asr and Beheshti hospitals in Zanjan, and Firozabadi and Haftom-Tir in Tehran) cities of Iran from 2009 to 2010 . The study was approved by the ethics committee of metabolic disorder research center of Zanjan, and patients provided their signed consents. The study duration was 4 months.

We determined the prevalence of $25(\mathrm{OH}) \mathrm{D}$ deficiency and SHPT in 180 HD participants. The HD patients, who were older than 14 years and had been under HD for at least 6 months were selected for the study. Patients, who had a history of recurrent calcium kidney stones, patients that had received treatment with any medication that interfered with serum levels of vitamin $\mathrm{D}$, patients with vitamin $\mathrm{D}$ (oral or injected form) treatment during the preceding 6 months, and patients with a diagnosis of tertiary HPT and advanced liver disease were excluded from the study. Also, patients with a history of parathyroidectomy, uncontrolled hyperphosphatemia, and severe hypercalcemia were excluded.

Patients with level of 25(OH)D less than $30 \mathrm{ng} / \mathrm{mL}$ were considered as vitamin D deficient and patients with iPTH above 300pg/mL were known as sHPT (13). Patients were under HD 3 times a week and were treated with calcium carbonate, renagel and calcitriol, according to the level of calcium (Ca), phosphorus (P), and $\mathrm{iPTH}$, which continued during the study.

Fasting blood samples of calcium, phosphorus, alkaline phosphatase, albumin, 25(OH)D, and iPTH were obtained at base line, 2 months, and at the end of the study, if necessary.

Serum pre-dialysis blood samples were tested for calcium by Arsenazo, phosphorus by photometric, alkaline phosphatase by photometric, albumin by Bromocresol Green, 25(OH)D by Acetonitrile, and iPTH level by radioimmunoassay methods.

First, prevalence of $25(\mathrm{OH}) \mathrm{D}$ deficiency among patients on HD was evaluated. Then, patients with a lack of $25(\mathrm{OH}) \mathrm{D}$ were randomly divided in intervention and control groups. The interventional group received an intramuscular shot of cholecalciferol (vitamin D3), 300,000 units at the beginning and at the end of 2 months. This readministration was performed if level of 25(OH)D was still less than $30 \mathrm{ng} / \mathrm{mL}$. The control group received the placebo. Over 2 to 4 months after treatment, the data was collected and compared for the two groups, to assess effects of vitamin D on calcium, phosphorus, $\mathrm{Ca} \times \mathrm{P}$ and $\mathrm{iHPT}$.

Serum calcium concentration was corrected by serum albumin concentration as follows:

Corrected serum calcium $=$ Serum calcium levels measured $+0.8 \times(4$-albumin serum $)$

Duration of dialysis, age, and gender were extracted from the patients' records. Demographic information of patients was collected, as shown in Table1. The HD protocol for all patients was 4 hours with hemophane membranes, the average blood flow rate was 300 to $350 \mathrm{~mL} / \mathrm{minute}$, and bicarbonate basis was used for dialysate.

\subsection{Statistical Analysis}

Statistical analysis was performed using the SPSS software for windows (version 20). The t test was performed for comparing continuous variables of the 2 groups and paired t test for before and after data. Mann-Whitney U-test and Wilcoxon sign rank tests were used for non-normal variables. All of the statistical tests were 2-sided. P values of less than 0.05 were considered significant.

\section{Results}

One hundred and eighty participants ( 81 females (45\%) and 99 males (55\%), with a mean age of $56.25 \pm 12.67$ years) were selected for this study. Table 1 presents the characteristics of the participants.

Out of the 180 patients on HD ( 81 females (45\%) and 99 males (55\%)), 158 (87.8\%) (68 females (43\%) and 90 males (57\%), with mean age of $56.15 \pm 12.7)$ were $25(\mathrm{OH}) \mathrm{D}$ deficient (<30 ng/mL) and 22 (12.2\%) (13 females (59.1\%) and 9 males (40.9\%), with mean age of $56.95 \pm 12.2)]$ had $25(\mathrm{OH}) \mathrm{D}$ more than $30 \mathrm{ng} / \mathrm{mL}$.

The prevalence of sHPT (PTH $>300)$, according to vitD levels in patients with vitamin $\mathrm{D}<30 \mathrm{ng} / \mathrm{mL}$, was $113(71.5 \%)$ (46 females (40.7\%) and 67 males (59.3\%), with mean age of $55.78 \pm 12.5)$, and the prevalence in patients with vitamin $\mathrm{D} \geq 30 \mathrm{ng} / \mathrm{mL}$ was 9 (40.9\%) (4 females (44\%) and 5 males (56\%), with mean age of $61.56 \pm 8.3$ ).

Patients with vitamin D deficiency, who had sHPT, were randomly divided to intervention and control groups. There was not statistically significant difference between 
Table 1. Baseline Characteristics of the Study Population ${ }^{\mathrm{a}}$

\begin{tabular}{|c|c|c|c|c|}
\hline & Total & $25(\mathrm{OH}) \mathrm{D}<30 \mathrm{ng} / \mathrm{mL}$ & $25(\mathrm{OH}) \mathrm{D} \geq 30 \mathrm{ng} / \mathrm{mL}$ & PValue \\
\hline Age, $y$ & $56.25 \pm 12.6$ & $56.15 \pm 12.7$ & $56.95 \pm 12.2$ & $0.78^{\mathrm{b}}$ \\
\hline \multirow{3}{*}{ Gender } & $\mathrm{N}=180$ & $\mathrm{~N}=158$ & $\mathrm{~N}=22$ & \multirow{3}{*}{0.15} \\
\hline & $\mathrm{F}: 81(45)$ & F: $68(43)$ & F: $13(59.1)$ & \\
\hline & M: 99 (55) & M: 90 (57) & M: $9(40.9)$ & \\
\hline BMI, $\mathrm{kg} / \mathrm{m}^{2}$ & $24.90 \pm 3.4$ & $24.94 \pm 3.4$ & $24.61 \pm 3.1$ & 0.66 \\
\hline Duration of dialysis, $y$ & $3.21 \pm 1.8$ & $3.32 \pm 1.8$ & $2.41 \pm 1.4$ & 0.024 \\
\hline Alb, mg/dL & $3.83 \pm 0.6$ & $3.84 \pm 0.6$ & $3.76 \pm 0.5$ & $0.48^{\mathrm{b}}$ \\
\hline $\mathrm{Ca}, \mathrm{mg} / \mathrm{dL}$ & $9.24 \pm 0.8$ & $9.22 \pm 0.8$ & $9.42 \pm 0.9$ & 0.32 \\
\hline $\mathrm{P}, \mathrm{mg} / \mathrm{dL}$ & $4.97 \pm 1.5$ & $4.93 \pm 1.5$ & $5.25 \pm 1.4$ & $0.11^{\mathrm{b}}$ \\
\hline $\mathbf{C a} \times \mathbf{P}$ & $45.84 \pm 13.7$ & $45.32 \pm 13.6$ & $49.58 \pm 13.9$ & $0.17^{\mathrm{b}}$ \\
\hline Bun & $59.73 \pm 17.0$ & $60.9 \pm 17.6$ & $57.18 \pm 11.5$ & 0.57 \\
\hline $\mathbf{C r}$ & $8.36 \pm 2.5$ & $8.19 \pm 2.3$ & $7.40 \pm 1.8$ & 0.08 \\
\hline Alkaline phosphatase, IU/L & $501.24 \pm 419.3$ & $507.39 \pm 408.4$ & $503.05 \pm 512.3$ & $0.23^{\mathrm{b}}$ \\
\hline 25(OH)D, ng/mL & $17.29 \pm 14.7$ & $13.48 \pm 6.4$ & $49.41 \pm 17.9$ & $<0.001^{\mathrm{b}}$ \\
\hline iPTH, pg/mL & $486.87 \pm 327.9$ & $460.03 \pm 263.8$ & $329.7 \pm 312.1$ & $0.011^{\mathrm{b}}$ \\
\hline iPTH & & & & $<0.001$ \\
\hline$<150$ & $24(13.3)$ & $14(8.9)$ & $10(45.5)$ & \\
\hline $150-300$ & $34(18.9)$ & $31(19.6)$ & $3(13.6)$ & \\
\hline$\geq 300$ & $122(67.8)$ & $113(71.5)$ & $9(40.9)$ & \\
\hline
\end{tabular}

Abbreviations: Alb, Albumin; Ca, calcium; P, Phosphorus; 25(OH)D, 25-hydroxy vitamin D; iPTH, intact parathyroid hormone.

${ }^{a}$ Values are expressed as mean \pm standard deviation or No. (\%).

${ }^{\mathrm{b}}$ Mann-Whitney U test.

the two groups at the baseline in terms of gender, age, duration of HD, blood urea nitrogen (BUN), Alb, Ca, Creatinine $(\mathrm{Cr}), \mathrm{P}$, and serum levels of $25(\mathrm{OH}) \mathrm{D}$ and iPTH $(\mathrm{P}>$ $0.05)$, as shown in Table 2.

The mean of body mass index (BMI) was $24.91 \pm 3.3$ $\mathrm{kg} / \mathrm{m}^{2}$ in the intervention group and $24.88 \pm 2.8 \mathrm{~kg} / \mathrm{m}^{2}$ in the control group $(\mathrm{P}=0.78)$. There was no statistically significant correlation between serum 25(OH) D levels, serum albumin $(\mathrm{P}=0.43)$, and $\mathrm{BMI}(\mathrm{P}=0.59)$.

Two months after the first intramuscular shot of vitamin D3, blood levels of Ca, P, Alk p, iPTH, and 25(OH)D serum were compared between the 2 groups as shown in Table 3.

In the intervention group, consisting of 57 patients, 2 months after the first injection, 51 (89.5\%) patients obtained a $25(\mathrm{OH}) \mathrm{D}$ level, which was increased from $13.85 \pm$ 6.5 to $48.5 \pm 20.7$ ( $\mathrm{P}<0.001)$, and 6 (10.5\%) patients had 25(OH)D level, which was less than $30(\mathrm{P}<0.001)$.

In the control group consisting of 56 patients, 5 (8.9\%) patients had 25(OH)D level, which was increased and 51 (91.9\%) patients had 25(OH)D level, which was less than 30.
In total, 25(OH)D level increased from $11.93 \pm 5.3$ to $13.75 \pm$ $8.8,(\mathrm{P}=0.08)$. Thus, the intervention group showed significant changes in comparison to the control group.

In the intervention group with 57 patients, 2 months after the first injections, in 44 (77.2\%) patients, amounts of iPTH was reduced from $567.2 \pm 276.5$ to $282.7 \pm 183.6$, $(\mathrm{P}<$ 0.001). However, in the control group, there was no significant change in the amount of iPTH. Changes in other factors in both groups before and after the intervention are shown in Table 3.

Two months after the first intramuscular shot of vitamin D3, 6 patients in the intervention group still had 25(OH)D level of less than $30 \mathrm{ng} / \mathrm{mL}$ and received 300,000 units of vitamin D3, as the beginning of the study.

Two months after the treatment, the data was collected and efficacy of vitamin D3 on calcium, phosphorus, Ca $\times \mathrm{P}$, and iPTH was assessed and analyzed. In 6 patients, $25(\mathrm{OH}) \mathrm{D}$ level had reached the normal range and in 5 patients, $\mathrm{iPTH}$ level was reached less than $300 \mathrm{pg} / \mathrm{mL}$.

The results of analysis of various parameters were as follows; 25(OH) D, $45.63 \pm 24.7$; iPTH, $201.16 \pm 90.5$; cal- 
Table 2. Baseline Laboratory Features of Intervention and Control Groups

\begin{tabular}{|c|c|c|c|}
\hline Variables & Intervention & Control & P Value \\
\hline \multirow{2}{*}{ Gender, $\mathrm{F} / \mathrm{M}$} & $\mathrm{F}: 26(45.6)$ & $\mathrm{F}: 20(35.7)$ & \multirow{2}{*}{0.35} \\
\hline & M: 31 (54.4) & M:36 (64.3) & \\
\hline Age, $y$ & $55.28 \pm 12.9$ & $56.29 \pm 12.2$ & 0.67 \\
\hline $\begin{array}{l}\text { Duration of } \\
\text { dialysis, } y\end{array}$ & $3.72 \pm 2.5$ & $3.09 \pm 1.2$ & 0.44 \\
\hline BMI, $\mathrm{kg} / \mathrm{m}^{2}$ & $24.91 \pm 3.3$ & $24.88 \pm 2.8$ & 0.78 \\
\hline Alb, mg/dL & $3.87 \pm 0.5$ & $3.85 \pm 0.4$ & 0.81 \\
\hline $\mathrm{Ca}, \mathrm{mg} / \mathrm{dL}$ & $9.10 \pm 0.5$ & $9.05 \pm 0.9$ & 0.75 \\
\hline $\begin{array}{l}\text { Alkaline } \\
\text { phosphatase, } \\
\text { IU/L }\end{array}$ & $553.37 \pm 495.6$ & $556.30 \pm 436.6$ & $0.33^{\mathrm{a}}$ \\
\hline$P, \mathrm{mg} / \mathrm{dL}$ & $4.91 \pm 1.2$ & $5.29 \pm 1.7$ & $0.45^{\mathrm{a}}$ \\
\hline $\mathbf{C a} \times \mathbf{P}$ & $44.47 \pm 10.1$ & $47.92 \pm 16.7$ & $0.46^{\mathrm{a}}$ \\
\hline $\mathbf{C r}$ & $8.81 \pm 1.8$ & $8.29 \pm 2.2$ & 0.16 \\
\hline Bun & $64.5 \pm 17.4$ & $60.59 \pm 18.3$ & 0.25 \\
\hline iPTH, pg/mL & $567.23 \pm 276.7$ & $575.21 \pm 162.4$ & $0.09^{\mathrm{a}}$ \\
\hline $25(\mathrm{OH}) \mathrm{D}, \mathrm{ng} / \mathrm{mL}$ & $13.86 \pm 6.5$ & $11.93 \pm 5.3$ & $0.16^{\mathrm{a}}$ \\
\hline
\end{tabular}

${ }^{\mathrm{a}}$ Mann Whitney U test.

cium, $9.05 \pm 0.8 ; \mathrm{P}, 4.9 \pm 1.4$; albumin, $3.78 \pm 0.39$; and ALK p, $291.50 \pm 127.35$. A few remaining number of interventional group were not compared with control group.

From 57 patients of the intervention group, for whom iPTH levels were more than $300 \mathrm{pg} / \mathrm{mL}$ at the beginning of the study, 2 months after first injection of vitamin D3, iPTH in 10 (17.5\%) patients was reduced to less than $150(\mathrm{pg} / \mathrm{mL})$ and in 34 (59.6\%) patients, iPTH was within the range of 150 to $300(\mathrm{pg} / \mathrm{mL})$. While the amount of iPTH in all patients in the control group remained above $300 \mathrm{pg} / \mathrm{mL}$, no significant reduction was observed.

\section{Discussion}

One billion people in the world have lack or insufficient levels of vitamin D (14). Vitamin D deficiency and insufficiency is common in patients with chronic kidney disease. Patients with kidney failure are at greater risk of this deficiency (15). Higher levels of $25(\mathrm{OH})$ D are associated with better survival in patients with renal failure (16).

Cholecalciferol (vitamin D3) is a simple, well tolerated, and inexpensive supplement. We administrated 300,000 IU of intramuscular vitamin D3 at baseline and 2 months later to keep the serum $25(\mathrm{OH})$ D levels within the desired range. Our patients were under treatment of calcium phosphate binder (carbonate calcium and sevelamer) along with calcitriol. The effect of vitamin D3 on some variables such as serum calcium, phosphor, alkaline phosphates, product $\mathrm{Ca} \times \mathrm{P}$, and $\mathrm{iPTH}$ was evaluated.

This study showed that the majority of patients on HD (87.8\%) had insufficient levels of 25(OH)D. However, other studies reported the prevalence of $25(\mathrm{OH}) \mathrm{D}$ deficiency as $80 \%, 97 \%$, and $95.5 \%$ in patients on dialysis (15-17).

A number of studies have reported a prevalence for $25(\mathrm{OH}) \mathrm{D}$ deficiency that is lower than our results. Elisa Del Valle reported a prevalence of only $22.6 \%$ among patients on HD (18) and Guillermo suggested that $50 \%$ of patients with end-stage renal disease (ESRD) had low level of 25(OH)D (19).

The difference between results of various studies is probably related to race, nutrition status, environment situation, and/or amount of sun exposure.

In a study published in 2008, among 64 HD patients, serum $25(\mathrm{OH})$ D level had increased by $95 \%$ with 20,000 IU of VitD3 per week for 9 months and at the end of the study, serum $25(\mathrm{OH}) \mathrm{D}$ had reached more than $30 \mathrm{ng} / \mathrm{mL}$ in $48 \%$ of patients (20). In another study performed on $107 \mathrm{HD}$ patients with vitamin D deficiency, 100,000 IU of vitamin D3 was administered per month. After 15 months, over $90 \%$ of patients had serum 25(OH) D levels of more than $43 \mathrm{ng} / \mathrm{mL}$ (21).

In this study, patients were administered 300,000 IU of vitamin D3 at baseline and 2 months later, according to the severity of 25(OH) D deficiency. Serum 25(OH) D levels after the first injection during 2 months, increased to more than $30 \mathrm{ng} / \mathrm{mL}$ in $89.5 \%$ (51 out of 57) of patients. Patients in this study, reached the desired level of $25(\mathrm{OH}) \mathrm{D}$ in a shorter time, which may be related to the amount of vitamin D3 used or the race of the patients.

Multiple studies have examined the effect of vitamin D on serum PTH level in dialysis patients $(22,23)$. In dialysis patients, 25(OH) D, independent of 1, 25(OH)D3, could increase the absorption of calcium and phosphorus from the intestine and kidney (22). Also, 25(OH) D has a correlation with serum PTH level and indirect effect on bone absorption (23).

In this study, $67.8 \%$ of patients had hyperparathyroidism and there was a significant relationship between lack of 25(OH) D and hyperparathyroidism $(\mathrm{P}<0.001)$. Our study showed that vitamin D3 combined with calcitriol increases $25(\mathrm{OH}) \mathrm{D}(\mathrm{P}<0.001)$, significantly reduces iPTH $(\mathrm{P}$ $<0.001)$ and $\mathrm{Ca}(\mathrm{P}=0.005)$, and significantly increases the serum albumin level $(\mathrm{P}=0.06)$.

Geoffrey et al. examined the effect of combination therapy of cinacalcet with a low dose of vitamin D to control the concentration of calcium, phosphorus, and iPTH, patients on dialysis, who had sHPT (24). Patients had been administered 180 to $30 \mathrm{mg}$ of vitamin D, once daily for 8 weeks, 
Table 3. Comparison of Different Variables Between the Groups Two Months After Vitamin D3 Therapy

\begin{tabular}{|c|c|c|c|c|c|c|c|c|c|}
\hline \multirow[t]{2}{*}{ Variables } & \multicolumn{3}{|c|}{ Intervention $(\mathbf{n}=57)$} & \multicolumn{3}{|c|}{ Control $(n=56)$} & \multirow[t]{2}{*}{ Difference in Intervention Group } & \multirow[t]{2}{*}{ Difference in Control Group } & \multirow[t]{2}{*}{ PValue $^{\mathbf{a}}$} \\
\hline & Baseline & After 2 months & PValue $^{\mathrm{b}}$ & Baseline & After 2 Months & PValue $^{b}$ & & & \\
\hline $25(\mathrm{OH}) \mathrm{D}$ & $13.85 \pm 6.5$ & $48.5 \pm 20.7$ & $<0.001$ & $11.93 \pm 5.3$ & $13.75 \pm 8.8$ & 0.08 & $34.6 \pm 22.4$ & $1.82 \pm 6.0$ & $<0.001$ \\
\hline IPTH, pg/mL & $567.2 \pm 276.7$ & $282.7 \pm 183.6$ & $<0.001$ & $575.2 \pm 162.4$ & $553.3 \pm 179.0$ & 0.005 & $-284.4 \pm 168.3$ & $-21.89 \pm 130.7$ & $<0.001$ \\
\hline Alb, mg/dL & $3.87 \pm 0.5$ & $4.00 \pm 0.4$ & 0.068 & $3.85 \pm 0.4$ & $4.05 \pm 0.5$ & 0.021 & $-0.15 \pm 0.6$ & $-0.19 \pm 0.6$ & 0.94 \\
\hline $\mathrm{Ca}, \mathrm{mg} / \mathrm{dL}$ & $9.10 \pm 0.5$ & $8.76 \pm 0.7$ & 0.005 & $9.05 \pm 0.9$ & $8.96 \pm 0.8$ & 0.31 & $0.34 \pm 0.8$ & $0.09 \pm 0.6$ & 0.067 \\
\hline $\mathrm{P}, \mathrm{mg} / \mathrm{dL}$ & $4.90 \pm 1.2$ & $5.21 \pm 1.3$ & 0.100 & $5.29 \pm 1.7$ & $5.08 \pm 1.4$ & 0.12 & $-0.30 \pm 1.5$ & $0.20 \pm 0.6$ & 0.021 \\
\hline $\mathbf{C a} \times \mathbf{P}$ & $44.43 \pm 10.8$ & $45.21 \pm 10.6$ & 0.44 & $47.92 \pm 16.7$ & $45.77 \pm 14.6$ & 0.13 & $0.74 \pm 14.1$ & $-2.14 \pm 9.5$ & 0.12 \\
\hline Alk $p, \mathbf{I U} / \mathbf{L}$ & $553.37 \pm 495.6$ & $393.4 \pm 419.5$ & $<0.001$ & $556.3 \pm 496.7$ & $496.7 \pm 363.9$ & 0.049 & $159.9 \pm 237.1$ & $59.6 \pm 184.9$ & 0.011 \\
\hline
\end{tabular}

Mann Whitney U test.

b Wilcoxon sign ranks test.

and 2 months later the effect of treatment was checked. They concluded that low levels of vitamin D combined with cinacalcet effectively reduces $\mathrm{iPTH}$ and product $\mathrm{Ca} \times \mathrm{P}$.

Other studies have shown that administration of vitamin D2 improves deficient and insufficient level of 25(OH)D in patients on HD (25) and reduces the level of iPTH. These studies have also claimed that the precursor of vitamin $\mathrm{D}$ is not toxic and is effective for the prevention of renal osteodystrophy $(26,27)$.

Klantrzadh evaluated the results of 9 studies and found that supplementation of vitamin D, whether in oral or injection form, increases 25(OH)D level and declines iPTH level(19). The result of our study showed the same findings.

However, there is another study that showed a lack of inactive vitamin D is not associated with sHPT (28), and Vit D2 or Vit D3 are not able to suppress iPTH (29-32).

\subsection{Summary}

The role of $25(\mathrm{OH}) \mathrm{D}$ in the treatment of sHPT in patients on HD is unclear. In the present study, we assessed the prevalence of $25(\mathrm{OH}) \mathrm{D}$ deficiency among patients on HD and evaluated the effect of vitamin D3 in the control of sHPT.

The results of this study indicate that 25(OH)D deficiency was highly prevalent (87.8\%) in patients on HD, and it seemed that lower values are not related to gender. A correlation between serum level of vitamin D and BMI was not significant $(r=-0.04)$.

Vitamin D3 had an effect on suppression of sHPT ( $\mathrm{P}<$ 0.001). To the best of our knowledge, currently, there is no Iranian epidemiologic study for evaluation of prevalence of 25(OH)D deficiency in HD patients and its effects on iPTH. The results of this work showed that combined therapy of calcitriol and vitamin D3, effectively reduces plasma levels of iPTH and Ca among patients with sHPT. Since this strategy is a relatively new approach in clinical trials, further work is required to identify whether correction of $25(\mathrm{OH})$ D levels improves control of sHPT.

\subsection{Limitation}

In terms of follow up, there was no limitation since patients came to HD centers to perform HD. However, we need more patients during longer time periods to confirm our results.

\section{Acknowledgments}

The authors appreciate the metabolic disorder research center of Zanjan, Iran.

\section{Footnote}

\section{Conflict of interest: None.}

\section{References}

1. Goodman WG. The consequences of uncontrolled secondary hyperparathyroidism and its treatment in chronic kidney disease. Seminars in dialysis.. 2004; Wiley Online Library; pp. 209-16.

2. Tentori F, Blayney MJ, Albert JM, Gillespie BW, Kerr PG, Bommer J, et al. Mortality risk for dialysis patients with different levels of serum calcium, phosphorus, and PTH: the Dialysis Outcomes and Practice Patterns Study (DOPPS). Am J Kidney Dis. 2008;52(3):519-30. doi: 10.1053/j.ajkd.2008.03.020. [PubMed: 18514987].

3. Dobnig H, Pilz S, Scharnagl H, Renner W, Seelhorst U, Wellnitz B, et al. Independent association of low serum 25-hydroxyvitamin $\mathrm{d}$ and 1,25-dihydroxyvitamin d levels with all-cause and cardiovascular mortality. Arch Intern Med. 2008;168(12):1340-9. doi: 10.1001/archinte.168.12.1340. [PubMed: 18574092].

4. Giovannucci E, Liu Y, Hollis BW, Rimm EB. 25-hydroxyvitamin D and risk of myocardial infarction in men: a prospective study. Arch Intern Med. 2008;168(11):1174-80. doi: 10.1001/archinte.168.11.1174. [PubMed: 18541825].

5. Goodman WG. Recent developments in the management of secondary hyperparathyroidism. Kidney Int. 2001;59(3):1187-201. doi: 10.1046/j.1523-1755.2001.0590031187.x. [PubMed:11231381].

6. Block GA, Klassen PS, Lazarus JM, Ofsthun N, Lowrie EG, Chertow GM. Mineral metabolism, mortality, and morbidity in maintenance hemodialysis. J Am Soc Nephrol. 2004;15(8):2208-18. doi: 10.1097/01.ASN.0000133041.27682.A2. [PubMed: 15284307]. 
7. Dusso AS, Brown AJ, Slatopolsky E. Vitamin D. Am J Physiol Renal Physiol. 2005;289(1):F8-28. doi: 10.1152/ajprenal.00336.2004. [PubMed: 15951480].

8. Birge SJ, Miller R. The role of phosphate in the action of vitamin D on the intestine. J Clin Invest. 1977;60(5):980-8. doi: 10.1172/JCI108878. [PubMed: 908762].

9. Bailie GR, Massry SG, National Kidney F. Clinical practice guidelines for bone metabolism and disease in chronic kidney disease: an overview. Pharmacotherapy. 2005;25(12):1687-707. doi: 10.1592/phco.2005.25.12.1687. [PubMed: 16305288].

10. Eknoyan G, Levin NW. Impact of the new K/DOQI guidelines. Blood Purif. 2002;20(1):103-8. [PubMed: 11803166].

11. Brown AJ, Slatopolsky E. Drug insight: vitamin D analogs in the treatment of secondary hyperparathyroidism in patients with chronic kidney disease. Nat Clin Pract Endocrinol Metab. 2007;3(2):134-44. doi: 10.1038/ncpendmet0394. [PubMed:17237840].

12. Lips P, Wiersinga A, van Ginkel FC, Jongen MJ, Netelenbos JC, Hackeng $\mathrm{WH}$, et al. The effect of vitamin $\mathrm{D}$ supplementation on vitamin D status and parathyroid function in elderly subjects. $J$ Clin Endocrinol Metab. 1988;67(4):644-50. doi: 10.1210/jcem-67-4-644. [PubMed: 3417845].

13. Kennel KA, Drake MT, Hurley DL. Vitamin D deficiency in adults: when to test and how to treat. Mayo Clinic Proceedings.. 2010; Elsevier; pp. 752-8.

14. Naeem Z. Vitamin d deficiency- an ignored epidemic. Int J Health Sci (Qassim). 2010;4(1):V-VI. [PubMed: 21475519].

15. Melamed ML, Thadhani RI. Vitamin D therapy in chronic kidney disease and end stage renal disease. Clin J Am Soc Nephrol. 2012;7(2):35865. doi: 10.2215/CJN.04040411. [PubMed: 22193236].

16. Ko EJ, Kim BH, Jeong HY, Soe SU, Yang DH, Lee SY. Serum 25hydroxyvitamin $\mathrm{D}$ as a predictor of hospitalization-free survival in predialysis and dialysis patients with chronic kidney disease: a single-center prospective observational analysis. Kidney Res Clin Pract. 2016;35(1):22-8. doi: 10.1016/j.krcp.2015.12.004. [PubMed: 27069854].

17. Bansal B, Bansal S, Mithal A, Kher V, Marwaha R. Vitamin D deficiency in hemodialysis patients. Indian J Endocrinol Metab. 2012;16(2):270-3. doi: 10.4103/2230-8210.93749. [PubMed: 22470866].

18. Del Valle E, Negri AL, Aguirre C, Fradinger E, Zanchetta JR. Prevalence of $25(\mathrm{OH})$ vitamin D insufficiency and deficiency in chronic kidney disease stage 5 patients on hemodialysis. Hemodial Int. 2007;11(3):31521. doi: 10.1111/j.1542-4758.2007.00186.x. [PubMed: 17576296].

19. Diez GJR, Fassi J, Crucelequi S, Nuñez HR, Trillini M, Furci A, et al. 25-Hydroxy Vitamin D Levels in Hemodialysis-Requiring End-Stage Renal Disease Patients. Dialysis Transplant. 2008;37(10):388-90. doi: 10.1002/dat.20260.

20. Tokmak F, Quack I, Schieren G, Sellin L, Rattensperger D, Holland-Letz T, et al. High-dose cholecalciferol to correct vitamin D deficiency in haemodialysis patients. Nephrol Dial Transplant. 2008;23(12):4016-20. doi: 10.1093/ndt/gfn367. [PubMed: 18593741].

21. Jean G, Souberbielle JC, Chazot C. Monthly cholecalciferol administration in haemodialysis patients: a simple and efficient strategy for vitamin D supplementation. Nephrol Dial Transplant. 2009;24(12):3799805. doi: 10.1093/ndt/gfp370. [PubMed: 19622574].

22. Fleet JC, Schoch RD. Molecular mechanisms for regulation of in testinal calcium absorption by vitamin D and other factors. Crit Rev Clin Lab Sci. 2010;47(4):181-95. doi: 10.3109/10408363.2010.536429. [PubMed: 21182397].

23. Bikle DD. Vitamin D and bone. Curr Osteoporos Rep. 2012;10(2):151-9. doi: 10.1007/s11914-012-0098-z. [PubMed: 22544628].

24. Block GA, Zeig S, Sugihara J, Chertow GM, Chi EM, Turner SA, et al Combined therapy with cinacalcet and low doses of vitamin D sterols in patients with moderate to severe secondary hyperparathyroidism. Nephrol Dial Transplant. 2008;23(7):2311-8. doi: 10.1093/ndt/gfno26. [PubMed: 18310602].

25. Taskapan H, Wei M, Oreopoulos DG. $25(\mathrm{OH})$ vitamin D3 in patients with chronic kidney disease and those on dialysis: rediscovering its importance. Int Urol Nephrol. 2006;38(2):323-9. doi: 10.1007/s11255006-0081-7. [PubMed:16868705].

26. DeVille J, Thorp ML, Tobin L, Gray E, Johnson ES, Smith DH. Effect of ergocalciferol supplementation on serum parathyroid hormone and serum 25-hydroxyvitamin D in chronic kidney disease. Nephrology (Carlton). 2006;11(6):555-9. doi: 10.1111/j.1440-1797.2006.00698.x. [PubMed: 17199797].

27. Jean G, Souberbielle JC, Lechevallier S, Chazot C. Kinetics of serum 25-hydroxyvitamin D in haemodialysis patients treated with monthly oral cholecalciferol. Clin Kidney J. 2015;8(4):388-92. doi 10.1093/ckj/sfv052. [PubMed: 26251704].

28. Gonzalez EA, Sachdeva A, Oliver DA, Martin KJ.Vitamin D insufficiency and deficiency in chronic kidney disease. A single center observational study. Am J Nephrol. 2004;24(5):503-10. doi: 10.1159/000081023. [PubMed: 15452403].

29. McClellan WM, Ramirez SP, Jurkovitz C. Screening for chronic kidney disease: unresolved issues. J Am Soc Nephrol. 2003;14(7 Suppl 2):S81-7. [PubMed: 12819308].

30. Coresh J, Selvin E, Stevens LA, Manzi J, Kusek JW, Eggers P, et al. Prevalence of chronic kidney disease in the United States. JAMA. 2007;298(17):2038-47. doi: 10.1001/jama.298.17.2038. [PubMed: 17986697 .

31. LaClair RE, Hellman RN, Karp SL, Kraus M, Ofner S, Li Q, et al. Prevalence of calcidiol deficiency in CKD: a cross-sectional study across latitudes in the United States. Am J Kidney Dis. 2005;45(6):1026-33. [PubMed: 15957131].

32. Andress DL. Vitamin d in health and disease: Vitamin D treatment in chronic kidney disease. Seminars in dialysis.. 2005; Wiley Online Library; pp. 315-21. 